\title{
Microscopic and molecular analysis of Babesia canis in archived and diagnostic specimens reveal the impact of anti- parasitic treatment and postmortem changes on pathogen detection
}

\author{
Doroteja Huber ${ }^{1}$, Ana Beck ${ }^{1 *}$, Željka Anzulović ${ }^{2}$, Daria Jurković ${ }^{3}$,Adam Polkinghorne ${ }^{4}$, Gad Baneth ${ }^{5}$ and Relja Beck ${ }^{3}$
}

\begin{abstract}
Background: Classification of Babesia parasites has traditionally relied on morphological differentiation based on piroplasm size and shape. Molecular typing has subsequently revealed a more complex taxonomy for these piroplasms than previously thought. To evaluate the factors that influence the morphology of Babesia species upon microscopic examination and hence, their taxonomic classification, we performed detailed characterizations of piroplasms from archival and prospective collections of cytological samples of dogs with piroplasmosis before and after death. Merozoite morphology and time of parasite disappearance following imidocarb dipropionate was also investigated.

Methods: The study was divided into a (i) review of archived cytological slides from confirmed cases of canine piroplasmosis, and (ii) a prospective study of smears and tissue imprints from 15 recently necropsied dogs. The latter group could be further sub-divided into a non-treated group and an imidocarb dipropionate-treated group. Exact times of treatment before death were reviewed. Additional blood smears prepared from the live dogs and taken before therapy were also evaluated in the latter group. Parasite burden per each slide was determined in both studies. The shape and size of merozoites were described from blood smears taken while the dogs were alive and from different organs during necropsy. The results of all measurements were statistically analyzed.

Results: The morphology and size of merozoites from live dogs corresponded to that of previously described 'large' Babesia. The morphology and size of merozoites were significantly different $(P<0.001)$ in postmortem samples, however, and more consistent in shape and size with piroplasm cells previously referred to as 'small' Babesia. PCR and sequencing confirmed B. canis as the causative agent of disease in all investigated dogs, including in postmortem negative tissue imprints from dogs treated at least $24 \mathrm{~h}$ before death.

Conclusions: Changes in the morphology of 'large' B. canis to 'small'-like Babesia observed by light microscopy appear to represent a common postmortem change. Classification of Babesia parasites into 'large' and 'small' Babesia using only microscopy of postmortem slides should be treated with caution. PCR-based methodologies for detection and molecular typing of Babesia spp. may prove valuable for investigating suspected cases of babesiosis following necropsy.
\end{abstract}

Keywords: Babesia canis, Merozoite morphology, Postmortem cytological detection, Influence of imidocarb dipropionate, Genotyping

\footnotetext{
* Correspondence: abeck@vef.hr

'Department of Veterinary Pathology, Faculty of Veterinary Medicine,

University of Zagreb, Vjekoslava Heinzela 55, 10000 Zagreb, Croatia

Full list of author information is available at the end of the article
} 


\section{Background}

Piroplasms are globally distributed, obligate intracellular hemotropic parasites of vertebrates from the genera Babesia, Theileria and Cytauxozoon [1, 2]. The name piroplasm comes from the fact that, within erythrocytes, the parasites often appear as pear-shaped on Romanowskystained cytological slides following microscopic examination [3]. Microscopic examination has played a central role in the early taxonomic classification of parasites in the genus Babesia, with these piroplasms primarily divided into 'large' and 'small' species based on the shape and size of their intra-erythrocytic stages [4-6] (Additional file 1: Table S1). Further taxonomic classification is not possible without the use of molecular typing approaches [7].

In domesticated dogs, babesiosis is an important and life-threatening hemolytic disease where $>10 \%$ of dogs may die despite treatment [8]. In regions endemic for canine babesiosis, every necropsied dog found with jaundice, anaemia, splenomegaly or pigmenturia is suspected to be a potential case of babesiosis, requiring further confirmation of possible protozoal aetiology. For this purpose and on the basis of morphological classification, all 'large' forms of Babesia in dogs were previously considered to be Babesia canis whereas all 'small' forms were designated as Babesia gibsoni [5]. Subsequently, the use of molecular techniques has enabled further differentiation of 'large' Babesia into a range of species including Babesia canis, Babesia vogeli, Babesia rossi and Babesia caballi, amongst others [9-11]. Within the 'small' Babesia group, the use of molecular methods has revealed more complexity, including the re-classification of previous 'small' Babesia species (e.g. Babesia vulpes) [12] into new species and, indeed, even different genera (e.g. Babesia microti-like's provisionally classification as Theileria annae) [13].

Postmortem identification of Babesia organisms is traditionally performed by microscopic examination of tissue imprints, smears and scrapings for morphological classification $[14,15]$. Beyond the issues with the accuracy of this classification scheme, the reliance on cytology as an antemortem and postmortem diagnostic tool is problematic in dogs treated during the hemolytic disease with drugs such as imidocarb dipropionate or other antipiroplasmic drugs. These drugs rapidly decrease the numbers of viable merozoites present in the circulation leading to parasite clearance [16] and raise the potential for 'false-negative' results following microscopic examination. As an alternative to microscopic examination, molecular detection of pathogens from stained slides or tissue imprints has been shown to be a useful tool for pathogen genotyping for protozoan parasites such as Leishmania or Cryptosporidium [17-19], particularly for retrospective cases where only cytological slides may be available instead of fresh or frozen tissue $[19,20]$.
Here, we compared and contrasted the use of microscopic and molecular characterization of piroplasms from stained archival slides and tissues originating from dogs with piroplasmosis. In doing so, the impacts that time of dog's death and treatment with imidocarb dipropionate had on the microscopic detection and description of these piroplasms were also assessed.

\section{Methods}

\section{Samples}

Samples for analysis in this study were divided into (i) retrospective samples in the form of archival slides and; (ii) prospectively collected samples from recently necropsied dogs. The former group (Group A), consisted of 14 archived Romanowsky-type stained cytological slides, previously microscopically confirmed to be positive for canine piroplasmosis (Table 1). Slides either consisted of clinical blood smears (CBS; $n=5$ ) or different postmortem organ imprints $(n=9)$ as described in Table 1 .

The prospective study (Group B) included 143 postmortem slides and eight related CBS cytological slides obtained from different tissues of 15 dogs with gross findings consistent with hemolytic disease, necropsied

Table 1 Parasite burden and genotyping results from archival cytological slides (Group A)

\begin{tabular}{|c|c|c|c|c|c|c|c|}
\hline \multirow[t]{2}{*}{ Samples } & \multirow[t]{2}{*}{ Tissue $^{a}$} & \multirow{2}{*}{$\begin{array}{l}\text { Year of } \\
\text { preparation }\end{array}$} & \multirow{2}{*}{$\begin{array}{l}\text { Parasite } \\
\text { burden }\end{array}$} & \multicolumn{4}{|c|}{ PCR protocols ${ }^{\mathrm{b}}$} \\
\hline & & & & cytb & 1 & 2 & 3 \\
\hline \multicolumn{8}{|c|}{ Postmortem samples } \\
\hline$A-1$ & Kidney & 2003 & $286(H)$ & + & + & + & + \\
\hline$A-2$ & Kidney & 2004 & $527(\mathrm{VH})$ & + & - & + & - \\
\hline$A-3$ & Spleen & 2007 & $134(M)$ & + & + & + & + \\
\hline$A-4$ & Spleen & 2008 & $4(L)$ & + & - & + & + \\
\hline$A-5$ & Spleen & 2009 & $97(\mathrm{~L})$ & + & - & + & + \\
\hline$A-6$ & Spleen & 2010 & $32(\mathrm{~L})$ & + & - & - & + \\
\hline A-7a & Kidney & 2014 & $43(L)$ & + & - & + & - \\
\hline$A-7 b$ & Myocardium & 2014 & $63(L)$ & + & + & + & + \\
\hline$A-8$ & Liver & 2014 & $439(\mathrm{VH})$ & + & + & + & + \\
\hline \multicolumn{8}{|c|}{ Clinical samples } \\
\hline$A-9$ & CBS & 2003 & $160(M)$ & + & - & + & - \\
\hline A-10 & CBS & 2007 & 78 (L) & + & + & + & + \\
\hline$A-11$ & CBS & 2010 & $143(\mathrm{M})$ & + & - & - & + \\
\hline A-12 & CBS & 2011 & $112(\mathrm{M})$ & + & - & - & + \\
\hline$A-13$ & CBS & 2012 & $82(\mathrm{~L})$ & + & - & - & - \\
\hline
\end{tabular}

${ }^{a}$ Tissue used for cytological slide preparation

${ }^{b}$ Protocol 1: conventional Babesia/Theileria PCR using BAB1 and BAB2 primers for amplification of 560 bp 18S rRNA; Protocol 2: conventional Babesia/Theileria $P C R$ after DNA concentration and purification using BAB1 and BAB2 primers for amplification of 560 bp 18 S rRNA; Protocol 3, nested Babesia/Theileria PCR for amplification of $1750 \mathrm{bp} 18 \mathrm{~S}$ rRNA and $560 \mathrm{bp} 18 \mathrm{~S}$ rRNA in the first and second round, respectively

Abbreviations: CBS, clinical blood smears made from the cephalic vein blood of clinical patients; $L$, low parasite burden; $M$, moderate parasite burden; $\mathrm{H}$, high parasite burden; $\mathrm{VH}$, very high parasite burden; cytb, mammalian cytochrome $b$ 
during a one-year period from November 2014 to November 2015 (Table 2). Materials used in this study came from necropsies performed upon owners' request. All available clinical data regarding treatment and exact time of death were obtained from the referring veterinarians or the dog's owners (Table 2). Slides in Group B could be further subdivided based on whether the slides were prepared from dogs that received imidocarb dipropionate treatment before death (treated dogs, subgroup $\mathrm{T}$ ) or were untreated (subgroup NT). In most cases, 10 cytological slides were obtained from each dog of subgroups NT and T, including postmortem blood smears, scrapings from the myocardium and skeletal muscle, and touch imprints from bone marrow, brain, kidney, liver, lungs, lymph node and spleen. For molecular confirmation of piroplasmosis in Group B, both kidney and myocardium tissues were also collected from all carcasses and stored at $-20{ }^{\circ} \mathrm{C}$. Fresh tissues were sampled from the exact cut surface location on the organs where the myocardium scrapings and kidney imprints were obtained for the purpose of preparing slides. In eight cases (dogs NT-1, T-1, T-2, T-3, T-5, T-6, T-7 and T-9), a blood sample was also collected in the clinic into an ethylenediaminetetraacetic acid containing tube during the course of the disease or prior the imidocarb dipropionate treatment and stored at $-20{ }^{\circ} \mathrm{C}$ for molecular analysis. In all eight cases mentioned above, a piroplasmosis positive CBS was available for microscopic reevaluation. Exceptions were dogs T-4 and T-8 for which CPBs were not submitted, although were found positive for the presence of piroplasms by referring clinicians who discarded the slides after microscopic confirmation of diagnosis.

\section{Cytological evaluation of clinical and postmortem samples}

Regardless of sampling technique (blood smears, tissue imprints or scrapings), cytological slides from all groups were air dried, stained with a Romanowsky-type stain and stored at room temperature in a dry and dark place protected from dust.

Light microscopy evaluation involved detection of piroplasms using an objective magnification of $40 \times$ to search the entire surface of the slide. When detected, the morphology of merozoites was described using an oil immersion objective (magnification 100x), and piroplasms were described using terms such as pear-shaped, round, oval, pleomorphic or signet ring-shaped (termed trophozoite in some studies). The dominant morphologic type of piroplasms found was estimated, evaluating up to 100 merozoites present per slide in 10 slides from 10 different tissues from each necropsied dog. The sizes of merozoites expressed in $\mu \mathrm{m}$ were measured with the software Cell^ ${ }^{\wedge}$ (Olympus Soft Imaging Solutions $\mathrm{GmbH}$, Muenster, Germany) for up to 100 merozoites on CBS and tissue slides. The location of merozoites (intraerythrocytic or free in the background of the cytologic slide), as

Table 2 Parasite burden, treatment data and time of necropsy for the non-treated (NT) and treated (T) subgroups of dogs in Group B

\begin{tabular}{|c|c|c|c|c|c|c|c|c|c|c|c|c|c|}
\hline \multirow[t]{2}{*}{ No. } & \multirow[t]{2}{*}{ CBS } & \multicolumn{10}{|c|}{ Postmortem samples } & \multirow{2}{*}{$\begin{array}{l}\text { Treatment } \\
\text { timing }^{a}\end{array}$} & \multirow{2}{*}{$\begin{array}{l}\text { Time of } \\
\text { necropsy }^{b}\end{array}$} \\
\hline & & Blood & $\begin{array}{l}\text { Bone } \\
\text { marrow }\end{array}$ & Brain & Kidney & Liver & Lung & $\begin{array}{l}\text { Lymph } \\
\text { node }\end{array}$ & Myocardium & $\begin{array}{l}\text { Skeletal } \\
\text { muscle }\end{array}$ & Spleen & & \\
\hline$\overline{N T-1}$ & na & na & $27(\mathrm{~L})$ & $492(\mathrm{VH})$ & $83(\mathrm{~L})$ & $59(\mathrm{~L})$ & $158(M)$ & na & $342(\mathrm{VH})$ & 0 & $41(\mathrm{~L})$ & na & 36 \\
\hline NT-2 & na & $36(L)$ & $324(\mathrm{VH})$ & $481(\mathrm{VH})$ & $423(\mathrm{VH})$ & $163(M)$ & $319(\mathrm{VH})$ & $114(\mathrm{M})$ & $361(\mathrm{VH})$ & $109(H)$ & $320(\mathrm{VH})$ & na & 0 \\
\hline NT-3 & na & $43(L)$ & $32(\mathrm{~L})$ & $72(\mathrm{~L})$ & $40(\mathrm{~L})$ & $49(\mathrm{~L})$ & $39(\mathrm{~L})$ & 0 & $57(\llcorner)$ & 0 & $104(H)$ & na & 36 \\
\hline NT-4 & na & $29(\mathrm{~L})$ & $17(\mathrm{~L})$ & $84(\mathrm{~L})$ & $58(\mathrm{~L})$ & $52(\mathrm{~L})$ & $60(\mathrm{~L})$ & 0 & $52(\mathrm{~L})$ & na & $39(\mathrm{~L})$ & na & 50 \\
\hline NT-5 & na & $49(\mathrm{~L})$ & $22(\mathrm{~L})$ & $235(H)$ & $202(H)$ & $68(L)$ & $79(\mathrm{~L})$ & $54(\mathrm{~L})$ & $226(H)$ & $159(H)$ & $137(H)$ & na & 48 \\
\hline NT-6 & $159(\mathrm{M})$ & $125(\mathrm{M})$ & $347(\mathrm{VH})$ & $286(H)$ & $320(\mathrm{VH})$ & $157(H)$ & $82(\mathrm{~L})$ & $24(\mathrm{~L})$ & na & $123(H)$ & $109(H)$ & na & 40 \\
\hline T-1 & $81(\mathrm{~L})$ & $29(\mathrm{~L})$ & $207(H)$ & $161(\mathrm{M})$ & $207(H)$ & $139(\mathrm{M})$ & $41(\mathrm{~L})$ & $217(H)$ & $232(H)$ & $205(H)$ & $184(\mathrm{M})$ & 6 & 17 \\
\hline $\mathrm{T}-2$ & $138(M)$ & $25(\mathrm{~L})$ & $322(\mathrm{VH})$ & $478(\mathrm{VH})$ & $413(\mathrm{VH})$ & $193(\mathrm{M})$ & $90(\mathrm{~L})$ & $56(\mathrm{~L})$ & $361(\mathrm{VH})$ & 0 & $309(H)$ & 6 & 21 \\
\hline $\mathrm{T}-3$ & $94(\mathrm{~L})$ & $47(\mathrm{~L})$ & $21(L)$ & $312(\mathrm{VH})$ & $92(\mathrm{~L})$ & $83(\mathrm{~L})$ & $118(\mathrm{M})$ & $34(\mathrm{~L})$ & $134(\mathrm{M})$ & $48(\mathrm{~L})$ & $57(\mathrm{~L})$ & 10 & 2 \\
\hline $\mathrm{T}-4$ & na & 0 & 0 & 0 & 0 & 0 & 0 & 0 & 0 & 0 & 0 & 10 & 6 \\
\hline T-5 & $164(\mathrm{M})$ & $103(\mathrm{M})$ & 0 & 0 & 0 & 0 & $8(L)$ & 0 & 0 & 0 & 0 & 24 & 0 \\
\hline T-6 & $51(\mathrm{~L})$ & 0 & 0 & 0 & 0 & 0 & 0 & 0 & 0 & 0 & 0 & 24 & 11 \\
\hline T-7 & $47(\mathrm{~L})$ & 0 & 0 & 0 & 0 & 0 & 0 & 0 & 0 & na & 0 & 24 & 1 \\
\hline T-8 & na & 0 & 0 & 0 & 0 & 0 & 0 & 0 & 0 & na & 0 & 24 & 3 \\
\hline T-9 & $73(\mathrm{~L})$ & 0 & 0 & 0 & 0 & 0 & 0 & 0 & 0 & na & 0 & 48 & 20 \\
\hline
\end{tabular}

aHours before death

${ }^{\mathrm{b}}$ Hours after death. Infection with B. canis was confirmed by PCR in organ samples from all dogs

Abbreviations: No., dog number; CBS, clinical blood smears made from the cephalic vein blood of clinical patients; na, not applicable; L, low parasite burden; M, moderate parasite burden; $\mathrm{H}$, high parasite burden; $\mathrm{VH}$, very high parasite burden 
well as the maximum number of parasites, present within single erythrocytes, was recorded per each slide, respectively. Parasite burden per each slide was scored as 'low' if the total number of counted merozoites found was $\leq 100$, 'moderate' (101-200 merozoites), 'high' (201-300 merozoites) and 'very high' (> 300 merozoites). Criteria for estimation of the total number of merozoites were determined by counting of intraerythrocytic and free merozoites visible in high-power fields (magnification 40x) in 4000 erythrocytes. The number of merozoites rather than a number of parasitized erythrocytes was used because of merozoites on postmortem-prepared samples, especially in cases of postmortem autolysis, tend to be free and extracellular rather than in the erythrocyte. A falsely low parasite burden was avoided by counting intraerythrocytic as well as extracellular merozoites. As organ slides contain somatic cells, a variable number of fields were investigated so that 4000 erythrocytes and their immediate surroundings were evaluated per each tissue slide.

\section{Molecular analysis}

DNA was extracted from stained cytological slides from Group A. Before extraction of DNA from cytological slides, $30 \mu \mathrm{l}$ of ATL buffer (Qiagen, Hilden, Germany) was applied to each slide. Slides were then gently scraped with a sterile, disposable scalpel into sterile $1.5 \mathrm{ml}$ tubes (Eppendorf, Hamburg, Germany). Additionally, $150 \mu \mathrm{l}$ ATL buffer was added to the tube containing the sample to obtain a total of $180 \mu \mathrm{l}$. After adding $20 \mu \mathrm{l}$ of proteinase $\mathrm{K}$ (Qiagen), samples were vortexed for $15 \mathrm{~s}$ and pelleted by brief centrifugation. Digestion was performed at $56{ }^{\circ} \mathrm{C}$ for $45 \mathrm{~min}$. Extraction of DNA was performed using the QIAamp DNA Mini QIAcube Kit with Blood and body fluids protocol (Qiagen), according to the manufacturer's instructions, on an automated system (Qiacube, Qiagen).

In both subgroups of Group B (NT and T), where available, DNA was also extracted from $200 \mu \mathrm{l}$ of blood collected at the clinic from eight dogs (NT-6, T-1, T-2, $\mathrm{T}-3, \mathrm{~T}-5, \mathrm{~T}-6, \mathrm{~T}-7$ and T-9) using the Blood and body fluids protocol and following the manufacturer's instructions (Qiagen). Twenty mg of fresh frozen kidney and myocardium tissues collected at necropsy from all dissected dogs were digested for four hours in $180 \mu \mathrm{l}$ ATL buffer with $20 \mu \mathrm{l}$ of proteinase $\mathrm{K}$ at $56{ }^{\circ} \mathrm{C}$. Extraction of DNA was performed using an automated system and the Tissue protocol with same Kit, according to the manufacturer's instructions (Qiagen).

The final volume of all DNA extractions was $100 \mu \mathrm{l}$. Distilled water was used as a control in each round of DNA extraction. To prevent contamination, all procedures (DNA extraction, PCR preparation, the addition of DNA template to PCR reactions and PCR and capillary electrophoresis) were performed in separate rooms using disposable pipette tips, gloves and aprons. Positive and negative controls (Mastermix with $\mathrm{dH}_{2} \mathrm{O}$ instead of DNA, Mastermix with $\mathrm{dH}_{2} \mathrm{O}$ used as a control in DNA extraction) were included in all amplifications.

Cytological slides from Group A were first subjected to a control PCR for amplification of the mammalian cytochrome $\mathrm{b}$ gene, using the primers Cyt b1 (5'-CCA TCC AAC ATC TCA GCA TGA TGA AA-3') and Cyt b2 (5'-GCC CCT CAG AAT GAT ATT TGT CCT CA-3'), which amplify a fragment of 359 bp of the cytochrome B gene from mammals [21], to assess the potential presence of PCR inhibitors in DNA extracted from archival Romanowsky-type stained slides in Group A. All samples from Group A which were positive for mammalian cytochrome b were further subjected to three different PCR protocols for detection of the presence of Babesia DNA. The first protocol (Protocol 1) was a conventional PCR containing $5 \mu \mathrm{l}$ of extracted DNA from slides for amplification of $\mathrm{Ba}$ besia/Theileria DNA using the forward BAB1 5'-GTC TTG TAA TTG GAA TGA TGG-3' and the reverse BAB2 5'-CCA AAG ACT TTG ATT TCT CTC-3' for amplification of $560 \mathrm{bp}$ of the 18S rRNA following the protocol used by Beck et al. [9]. The second protocol (Protocol 2) used an identical conventional PCR protocol (Protocol 1), but it was performed on purified and concentrated DNA (from $100 \mu \mathrm{l}$ to final volume of $40 \mu \mathrm{l}$ ) with a QIAquick PCR Purification Kit (Qiagen), according to the manufacturer's instructions. The third PCR protocol (Protocol 3) was a nested PCR. The first reaction in the nested PCR was carried out on $2 \mu \mathrm{l}$ of DNA with the forward CRYPTO F 5'-AAC CTG GTT GAT CCT GCC AGT AGT CAT-3' and reverse CRYPTO R 5'-GAA TGA TCC TTC CGC AGG TTC ACC TAC-3' primers [22] for amplification of $1730 \mathrm{bp}$ of the $18 \mathrm{~S}$ rRNA gene. In the second nested PCR reaction, $5 \mu \mathrm{l}$ of PCR product from the first reactions were added and amplified with primers BAB1 and BAB2. For Group B, DNA from tissues and blood from subgroups NT and T were subjected to a conventional PCR reaction for amplification of Babesial Theileria DNA using Protocol 1 described above. A final volume of $50 \mu \mathrm{l}$ of PCR mixture consisted of $25 \mu \mathrm{l} \mathrm{GoTaq}{ }^{\circ}$ Colorless Master Mix and DNA/RNAase free water (Promega, Madison, WI, USA), $1 \mu \mathrm{l}$ of $10 \mathrm{pmol}$ of each primer and $5 \mu \mathrm{l}$ of extracted DNA.

Results of PCRs were evaluated by capillary electrophoresis with QIAxcel (Qiagen) using the QIAxcel DNA Fast Analysis kit, alignment markers (DNA QX Alignment Marker $15 \mathrm{bp} / 3 \mathrm{~kb}$ ) and marker sizes (QX DNA Size Marker 50-3000 bp). Amplified samples were purified using EXOSAP-it ${ }^{\oplus}$ (USB $^{\circ}$ Products AffyInc., Ohio, USA), according to the manufacturer's instructions, and sequenced in both directions by Macrogen Inc. (Amsterdam, The Netherlands). Sequences were assembled using the SeqMan Pro software, edited with the EditSeq software (Lasergene, DNASTAR, Madison 
WI, USA) and compared with available sequences using BLAST.

\section{Statistical analysis}

Statistical analyses were carried out using the Statistica 13.2 software (Dell, USA). Range and mean values were determined with the descriptive statistics command and rounded to two digits after the decimal point. Normality of distribution was determined by the Kolmogorov-Smirnov test, and none of the investigated groups followed a normal distribution $(P<0.05)$. The nonparametric Mann-Whitney U-test was used for calculation of statistical significance of the differences in parasite sizes. A $P$-value $<0.05$ was considered as statistically significant.

\section{Results}

Cytological evaluation of clinical and postmortem samples from archival and prospectively collected canine samples Merozoites detected in CBS slides from archival slides (Group A) and prospectively collected slides (Group B) showed the same range of morphologies. The dominant morphology was pear-shaped (Fig. 1a), but parasites also showed round (Fig. 1b), oval (Fig. 1b), pleomorphic (Fig. 1c) or signet ring-shaped morphologies which could be considered trophozoites (Fig. 1c). Forms resembling the Maltese cross (Fig. 1d) were also observed in a few erythrocytes of some dogs. Merozoites measured $3.75 \mu \mathrm{m}$ in length (range 1.54-4.2 $\mu \mathrm{m}, n=417$ ) by $1.88 \mu \mathrm{m}$ in width (range $1.2-2.7 \mu \mathrm{m} ; n=417$ ) in Group A, and 3.1 $\mu \mathrm{m}$ (range 1.4-5.7 $\mu \mathrm{m}, n=800$ ) in length by $2.0 \mu \mathrm{m}$ in width (range $1.5-2.5 \mu \mathrm{m} ; n=800$ ) in both subgroups (NT and T) of Group B. The morphology and size of merozoites are consistent with the previous descriptions of 'large' Babesia [4] (Additional file 1: Table S1). The merozoites were mostly located in erythrocytes, occasionally in reticulocytes (Fig. 1b) and rarely presented as free, extracellularly (Fig. 1a). Intracellular merozoites were usually paired (Fig. 1b), but they could also be single (Fig. 1c) and rarely four in forms resembling the Maltese cross (Fig. 1d).

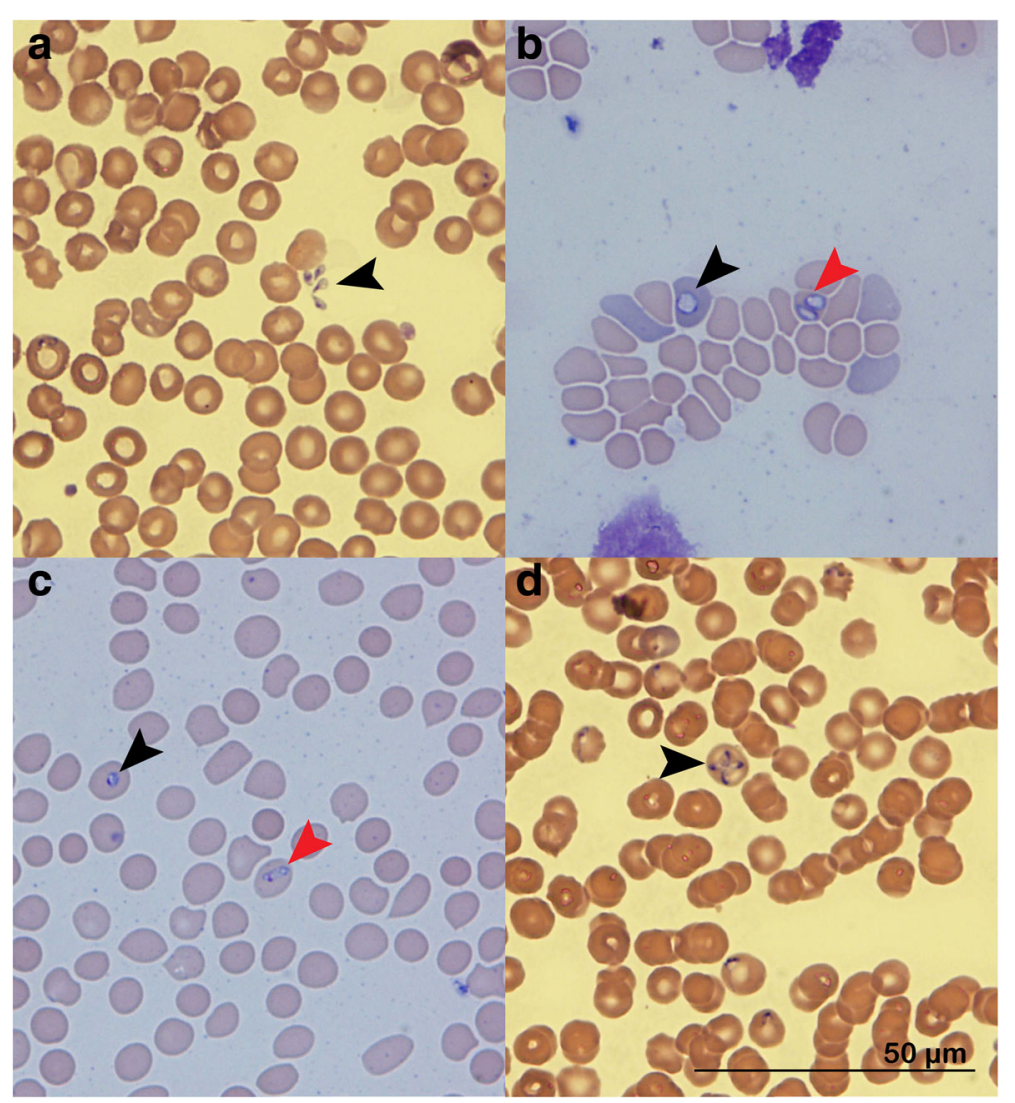

Fig. 1 Images of blood smears from dogs before treatment, Romanowsky-type staining, 100x. a Four pear-shaped extracellular merozoites (arrowhead) measuring $2.66 \times 1.45 \mu \mathrm{m}, 2.55 \times 1.2 \mu \mathrm{m}, 3.22 \times 1.85 \mu \mathrm{m}$ and $3.15 \times 1.21 \mu \mathrm{m}$, moderate parasite burden, dog A-9. b A reticulocyte containing one round merozoite (black arrowhead) measuring $3.42 \mu \mathrm{m}$ and an erythrocyte containing one oval merozoite measuring $4.03 \times$ $2.05 \mu \mathrm{m}$ and one round merozoite measuring $2.58 \mu \mathrm{m}$ (red arrowhead), low parasite burden, dog T-1. NCB11 (Nikon's blue) filter. c Two erythrocytes containing one signet-ring trophozoites-like parasite (black arrowhead) measuring $1.8 \mu \mathrm{m}$ and one pleomorphic merozoite (red arrowhead) measuring $2.13 \times 1.67 \mu \mathrm{m}$, low parasite burden, T-1. NCB11 (Nikon's blue) filter. $\mathbf{d}$ An erythrocyte containing four piriform merozoites (black arrowhead) measuring $2.53 \times 1.2 \mu \mathrm{m}, 1.96 \times 1.40 \mu \mathrm{m}, 2.23 \times 1.41 \mu \mathrm{m}$ and $2.21 \times 1.15 \mu \mathrm{m}$ with Maltese cross-like formation, moderate parasite burden, dog A-9 
To compare the potential changes in the morphology of detected piroplasms in postmortem samples, we examined nine archival tissue imprints from Group A (Table 1) and 139 Group B postmortem samples obtained from the six dogs in the NT subgroup $(n=56$ slides) and nine dogs in the T subgroup ( $n=83$ slides), respectively (Table 2). In these slides, piroplasms were dominantly found as pairs or in more numerous numbers after binary division within the erythrocytes (Fig. 2a, d).

Merozoites showed consistently different morphologies in all postmortem samples, similarly to that previously described for 'small' Babesia (Additional file 1: Table S1), when compared to the corresponding CBS slide for sampled dogs. In the postmortem slides, merozoites were shrunken, dominantly round (Figs. 2a, 3 and 4), but also pleomorphic (Fig. 2b), signet ring-shaped (Fig. 2b) or piriform in Maltese cross-like formation (Fig. 2c). In both Group A $(3.75 \pm 0.53 \mu \mathrm{m})$ and Group B $(3.1 \pm 0.73 \mu \mathrm{m})$, the mean length of merozoites in CBS smears was significantly longer $\left(U_{A}=0.00, n_{1 \mathrm{~A}}=417, n_{2 \mathrm{~A}}=538, P_{A}<0.001\right.$;
$\left.U_{B}=4606.5, n_{1 \mathrm{~B}}=800, n_{2 \mathrm{~B}}=900, P_{A}<0.001\right)$ than the length of merozoites on the corresponding postmortem tissue slides for Group A $(1.2 \pm 0.15 \mu \mathrm{m})$ and Group B $(1.2 \pm 0.27 \mu \mathrm{m})$. Similarly, the width of merozoites from CBS slides was also significantly $\left(U_{A}=8305.5, n_{1 \mathrm{~A}}=417\right.$, $n_{2 \mathrm{~A}}=538, P<0.001 ; U_{B}=9554, n_{1 \mathrm{~B}}=800, n_{2 \mathrm{~B}}=900$, $P<0.001)$ wider in both Group A $(1.88 \pm 0.41 \mu \mathrm{m})$ and Group B $(2.00 \pm 0.2 \mu \mathrm{m})$ slides compared to the corresponding postmortem tissue slides from Group A $(1.2 \pm 0.15 \mu \mathrm{m})$ and Group B dogs $(1.2 \pm 0.27 \mu \mathrm{m})$.

In terms of other variables, notably, when the number of intracellular parasites was higher (five or more; Fig. 3), intracellular merozoites of all groups were uniformly smaller in length $(0.8 \mu \mathrm{m}$; range $0.7-1.1 \mu \mathrm{m}$, $n=278$ and $0.9 \mu \mathrm{m}$; range $0.5-1.2 \mu \mathrm{m}, n=300$, respectively). In the extracellular space (Fig. 4), merozoites varied from 0.7 to $1.48 \mu \mathrm{m}$ (mean $1.2 \mu \mathrm{m} ; n=183$ ) in Group A, and 0.5 to $2.0 \mu \mathrm{m}$ (mean $1.2 \mu \mathrm{m} ; n=200$ ) for Group B slides, regardless of their number or organ slide.

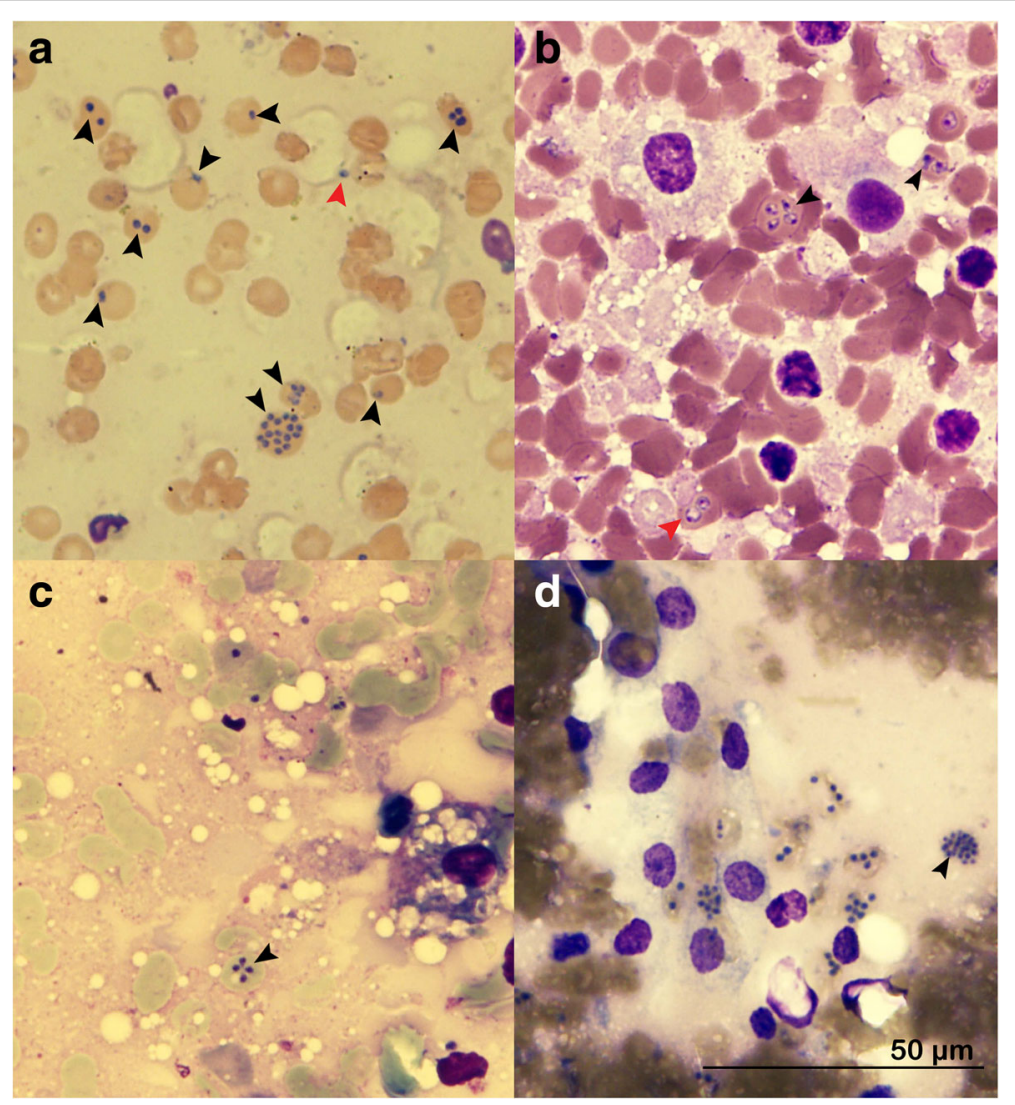

Fig. 2 Images of tissue imprints obtained during the necropsy, Romanowsky-type staining, 100x. a Nine erythrocytes containing from between one to 16 round B. canis merozoites (black arrowheads) and one free round merozoite (red arrowhead) measuring 0.87-1.2 $\mu$ m, high parasite burden in kidney tissue imprint, dog A-2. b Two erythrocytes (black arrowhead) containing two to four pleomorphic merozoites measuring $1.87-2.0 \mu \mathrm{m}$ in length and 1.0-1.45 $\mu \mathrm{m}$ in width and one erythrocyte (red arrowhead) containing two signet-ring shaped merozoites measuring 1.77-1.87 $\mu \mathrm{m}$, moderate parasite burden in spleen imprint, dog A-3. c A Maltese cross-like formation of merozoites measuring $1.57 \times 0.96 \mu \mathrm{m}, 1.23 \times 0.96 \mu \mathrm{m}, 1.40 \times$ $1.02 \mu \mathrm{m}$ and $1.02 \times 0-96 \mu \mathrm{m}$ within one erythrocyte (arrowhead), moderate parasite burden in liver imprint, dog NT-2. d An erythrocyte containing 20 round merozoites (arrowhead) measuring 0.5-1.4 $\mu \mathrm{m}$, high parasite burden in kidney imprint, dog A-1 


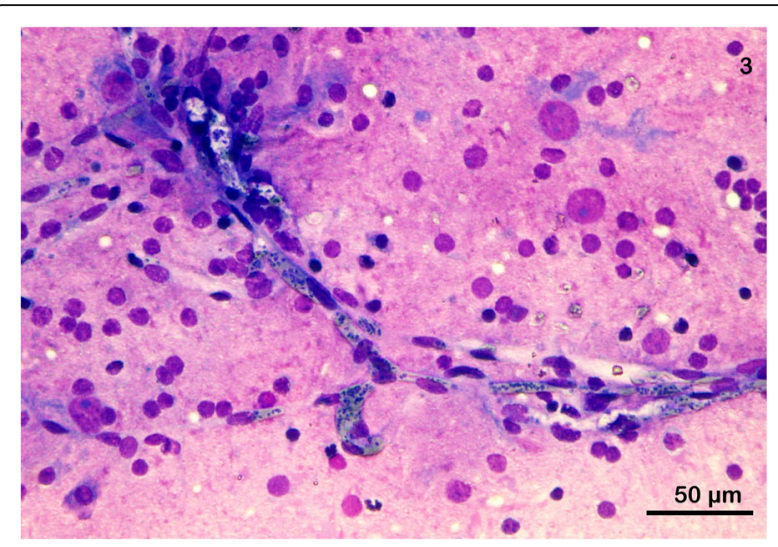

Fig. 3 Image of brain imprint obtained postmortal. Magenta background reflecting proteins and lipids from neuropil containing numerous nucleoli of glia cells. Irregular and parallel branching of capillary segments containing numerous erythrocytes heavily parasitized with a round to oval deep blue merozoites, very high parasite burden, dog NT-1, Romanowskytype staining, $40 \times$

The morphology of parasites on postmortem slides also did not appear to be related to the time of necropsy after death (Table 2). Parasites were preserved and of similar morphology in slides originating from fresh carcasses, and also in carcasses of dogs necropsied 48 and $50 \mathrm{~h}$ after death (NT-4 and NT-5; Table 2).

To investigate the impact of imidocarb dipropionate treatment on the cytological detection of merozoites within tissue slides prepared at post-mortem (Group B), the presence of merozoites between treated $(\mathrm{T})$ and untreated (NT) subgroups were compared (Table 2). In dogs from subgroup NT, merozoites were present in all or almost all slides from all dogs (Table 2). Negative organ slides in the subgroup NT included the lymph node and skeletal muscle (Table 2). In dogs from subgroup $\mathrm{T}$, the

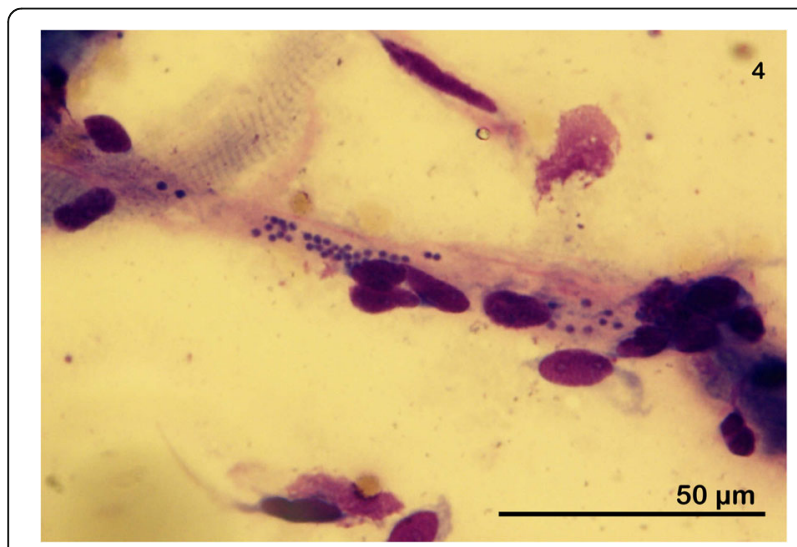

Fig. 4 Image of myocardial scraping obtained postmortal. Multiple fibrocytes and a single muscle cell fragment showing transversal striation. A single capillary segment containing free round deep blue merozoites, very high parasite burden, dog NT-1, Romanowsky-type staining, 100x presence of merozoites depended on the time of treatment before death. In two dogs treated six hours before death (T-1 and T-2), merozoites were found in CBS and almost all postmortem tissue slides (Table 2). In dog T-3 treated $10 \mathrm{~h}$ before death, merozoites were present in CBS and all postmortem slides, while in another dog (T-4) treated $10 \mathrm{~h}$ before death, merozoites were not found in postmortem slides. In the remaining dogs treated 24 to $48 \mathrm{~h}$ prior to post-mortem (T-5, T-6, T-7, T-8 and T-9), almost no merozoites could be found in post-mortem slides except for a postmortem blood smear and lung touch imprint from dog T-5 necropsied immediately after death (Table 2). No morphological differences could be observed in slides from $\mathrm{T}$ and NT subgroups where merozoites could be observed (data not shown).

Parasite burden in either subgroup was variable and inconsistent in different organ slides from the same dog as well as in the same organs originating from different dogs (Table 2). In general, piroplasms were most easily visualized in bone marrow, brain (Fig. 3), kidney, myocardium (Fig. 4) and the spleen based on merozoite counts across from samples from each tissue (Table 2).

\section{Molecular analysis of clinical and postmortem samples} from archival and prospectively collected canine samples In Group A, mammalian cytochrome B was successfully amplified from all CBS and tissue slides, confirming the absence of any potential PCR inhibitors. Babesia/Theileria DNA was successfully amplified with at least one out of three PCR protocols applied in 13 out of 14 slides analyzed (Table 1) from this group. Specifically, the conventional PCR protocol (Protocol 1) was successful in $35.7 \%$ $(5 / 14)$ of the tested samples, while using Protocols 2 and 3 , amplification of piroplasm DNA increased to $71.4 \%$ (10/14) PCR positivity although differences in the actual positivity of individual samples were different for these latter two protocols. More detailed examination revealed that, for the tissue slides, a higher sensitivity of Babesia/ Theileria DNA detection was achieved after implementation of DNA purification and concentration (Protocol 2) with PCR positivity of $88.9 \%$ (8/9) compared to $77.8 \%$ (7/ 9) for Protocol 3. Conversely for the CBS, Protocol 3 was found to achieve slightly higher PCR positivity $(60 \% ; 3 / 5)$ compared to Protocol 2 (40\%; 2/5). The success of DNA amplification was not correlated to parasite burden per each slide and DNA was amplified from samples with a low, moderate, high and very high number of merozoites, respectively (Table 1 ). Sequencing revealed that the DNA fragment amplified from all 13 slides was $100 \%$ identical with B. canis BBC1 isolate (GenBank: FJ209024). DNA sequence quality in Group A archived samples did not appear to be affected by the duration of archiving (Table 1).

All blood, kidney and myocardium samples from Group B were positive for Babesia/Theileria DNA, 
independent of the time of death or treatment (data not shown). All PCR amplified sequences were 100\% identical to the BBC1 isolate of B. canis (GenBank: FJ209024).

\section{Discussion}

Morphological differentiation of piroplasms in the genus Babesia is still routinely used for speciation, particularly in necropsy samples where samples for molecular diagnostics are typically not collected. In the current study, we detected different morphologies of Babesia merozoites in cytological slides from clinical and necropsy specimens from the same dogs. Molecular typing of these cases using DNA extracted from the cytological slides themselves, however, revealed that all piroplasms identified belonged to $B$. canis. This phenomenon was previously reported by Demeter et al. [15] in a puppy that died due to piroplasmosis, but the authors suspected the postmortem change in morphology was an exception and not the rule. Here, we present strong evidence that B. canis morphology changes from 'large' to apparently 'small' forms after the death of the host in both treated and non-treated dogs. The most likely explanation for the change in the size of the $B$. canis merozoites under cytological examination is generalized hypoxia, following the death of the dog [15]. The morphological change is not related to the cause of death or time of death as well as the time of treatment because, in fresh carcasses (i.e. dissected right after death), merozoites were already shrunken in all slides.

All dogs with suspicious piroplasmosis or with confirmed 'large' Babesia merozoites are routinely treated with the antibabesial drug imidocarb dipropionate in Croatia [23]. Imidocarb dipropionate is the preferred treatment because of its rapid therapeutic response and consistent host clearance of babesial parasites [16]. The absence of merozoites in treated dogs with imidocarb dipropionate can pose a challenge in the cytological diagnosis of piroplasmosis, as demonstrated in the current study. Both dogs treated six hours before death had merozoites in slides from most organs (Table 2). However, treatment of two dogs that died $10 \mathrm{~h}$ after drug application resulted in different outcomes: complete disappearance of merozoites in one dog, while the other dog still had visible merozoites on postmortem slides (Table 2). Parasite clearance was confirmed in all dogs treated with imidocarb dipropionate $24 \mathrm{~h}$ before death where merozoites were not found in postmortem samples examined. Dog T-5 also belonged to this group of dogs who lived an additional $24 \mathrm{~h}$ after imidocarb dipropionate application. Dog T-5 was necropsied minutes after death and, despite treatment, it had the exceptional finding of low numbers of merozoites still present on postmortem blood smear and lung imprint. Therefore, we conclude that postmortem cytological confirmation of babesiosis is unreliable in cases of treatment $24 \mathrm{~h}$ or more before death.
However, our results show that a suspicion that necropsied dogs died of hemolytic disease caused by $B$. canis can still be confirmed by conventional PCR and sequencing on postmortem obtained tissue as evidenced by the PCR detection of Babesia DNA in all of these dogs (Table 2).

In cases where fresh or frozen samples are not available for molecular diagnostics, archived material, such as blood or tissue slides can still be useful for PCR as it is routinely done for parasites from the genera Plasmodium and Leishmania [19, 20, 24]. Despite archiving of up to 12 years, DNA was still amplified and sequenced from the samples in the current study (Table 1). It seems that Romanowsky-type staining conserves DNA from degrading probably due to the fixation with ethanol $[19,20,24]$. The best results were obtained with the samples from Group A Protocol 2 (purified and concentrated DNA) and Protocol 3 (nested PCR) likely due to higher amounts of available DNA in the sample and a higher number of amplification cycles performed, enhancing the sensitivity of the reactions. Protocol 2 was more suitable for amplification of DNA from tissue slides, while the Protocol 3 (nested) PCR, although equally successful as protocol 2 overall, was better in amplifying DNA from blood smears.

\section{Conclusions}

In the current study, we have confirmed that a change in morphology of 'large' B. canis to 'small'-like Babesia morphology, as observed by light microscopy, consistently takes place postmortem. These findings also suggest that classification of Babesia parasites into 'large' and 'small' Babesia could lead to false conclusions on species involved if postmortem slides are analyzed unless genotyping is performed. We, therefore, recommend that in necropsy cases with a history of antibabesial treatment or without historical data, PCR diagnostic testing should be utilized over microscopy since, after $24 \mathrm{~h}$, it was almost impossible to detect merozoites in tissue slides.

\section{Additional file}

Additional file 1: Table S1. Literature review of Babesia classification into 'large' and 'small' based on size of merozoites. (XLSX 12 kb)

\section{Abbreviations \\ CBS: clinical blood smears from the cephalic vein of clinical-ill dogs; cytb: mammalian cytochrome $b$; na: not applicable}

\section{Acknowledgements}

We thank the Journal of Comparative Pathology for awarding Doroteja Huber with the Journal of Comparative Pathology junior travel bursary, which allowed her to present part of the work published in this article at the 33rd Annual Meeting of the European Society of Veterinary Pathology, on September 2015 in Helsinki, Finland. We also acknowledge Marko Poletto for technical support, Valeria Benko for clinical blood samples collection, and Sanja Duvnjak and Irena Reil for helping with PCR. This research was funded by GENOTICKTRECK, Croatian Science Foundation Project number: 1957. 


\section{Funding}

This research was funded by GENOTICKTRACK, Croatian Science Foundation Project number: 1957

\section{Availability of data and materials}

The data sets supporting the conclusions of this article are included in the article.

\section{Authors' contributions}

DH performed necropsies with sample collection, analyzed and interpreted cytological findings, performed molecular analyses and drafted the manuscript. $A B$ designed the study, performed sample collection, analyzed and interpreted cytological findings and drafted and edited the manuscript.

ŻA assisted with figure preparation, performed molecular analyses from archival samples and assisted with preparation of the manuscript. GB edited and contributed to the drafting of the manuscript. DJ assisted with parasitological and genotyping analyses. AP assisted with data analysis and contributed to the drafting and editing of the manuscript. RB designed the study, performed parasitological and genotyping analyses, drafted and edited the manuscript. All authors read and approved the final manuscript.

\section{Ethics approval and consent to participate}

This study was approved by the institutional ethics committee of the Faculty of Veterinary Medicine, University of Zagreb, permit number 251-61-01/139-15-2.

\section{Consent for publication}

Not applicable.

\section{Competing interests}

The authors declare that they have no competing interests.

\section{Publisher's Note}

Springer Nature remains neutral with regard to jurisdictional claims in published maps and institutional affiliations.

\section{Author details}

'Department of Veterinary Pathology, Faculty of Veterinary Medicine, University of Zagreb, Vjekoslava Heinzela 55, 10000 Zagreb, Croatia. ${ }^{2}$ Faculty of Veterinary Medicine, University of Zagreb, Vjekoslava Heinzela 55, 10000 Zagreb, Croatia. ${ }^{3}$ Department for Bacteriology and Parasitology, Croatian Veterinary Institute, Savska cesta 143, 10000 Zagreb, Croatia. ${ }^{4}$ Centre for Animal Health Innovation, University of the Sunshine Coast, Sippy Downs, Australia. ${ }^{5}$ Koret School of Veterinary Medicine, Hebrew University, Rehovot, Israel.

Received: 31 May 2017 Accepted: 29 September 2017

Published online: 18 October 2017

\section{References}

1. Alvarado-Rybak M, Solano-Gallego L, Millan JA. review of piroplasmid infections in wild carnivores worldwide: importance for domestic animal health and wildlife conservation. Parasit Vectors. 2016;9:538.

2. Allsopp MTEP, Allsopp BA. Molecular sequence evidence for the reclassification of some Babesia species. Ann N Y Acad Sci. 2006;1081:509-17.

3. Uilenberg G. Babesia - A historical overview. Vet Parasitol. 2006:138:3-10.

4. Solano-Gallego L, Sainz A, Roura X, Estrada-Pena A, Miro GA. review of canine babesiosis: the European perspective. Parasit Vectors. 2016;9:336.

5. Boozer AL, Macintire DK. Canine babesiosis. Vet Clin North Am Small Anim Pract. 2003:33:885-904.

6. Solano-Gallego L, Baneth G. Babesiosis in dogs and cats - expanding parasitological and clinical spectra. Vet Parasitol. 2011;181:48-60.

7. Uilenberg G, Franssen FFJ, Perie NM, Spanjer AAM. Three groups of Babesia canis distinguished and a proposal for nomenclature. Vet Quart. 1989:11:33-40

8. Matijatko V, Kiš I, Torti M, Brkljačić M, Kučer N, Barić Rafaj R, et al. Septic shock in canine babesiosis. Vet Parasitol. 2009;162:263-70

9. Beck R, Vojta L, Mrljak V, Marinculić A, Beck A, Živičnjak T, et al. Diversity of Babesia and Theileria species in symptomatic and asymptomatic dogs in Croatia. Int J Parasitol. 2009:39:843-8.

10. Birkenheuer AJ, Neel J, Ruslander D, Levy MG, Breitschwerdt EB. Detection and molecular characterization of a novel large Babesia species in a dog. Vet Parasitol. 2004;124:151-60.
11. Lehtinen LE, Birkenheuer AJ, Droleskey RE, Holman PJ. vitro cultivation of a newly recognized Babesia sp. in dogs in North Carolina. Vet Parasitol. 2008;151:150-7.

12. Baneth $G$, Florin-Christensen M, Cardoso L, Schnittger L. Reclassification of Theileria annae as Babesia vulpes sp. nov. Parasit Vectors. 2015;8:207.

13. Zahler $M$, Rinder $H$, Schein $E$, Gothe R. Detection of a new pathogenic Babesia microti-like species in dogs. Vet Parasitol. 2000;89:241-8.

14. Valli VEO, Kiupel M, Bienzle D, Wood RD. Hematopoietic System. In: Grant Maxie M, editor. Jubb, Kennedy and Palmer's Pathology of Domestic Animals. Elsevier; 2016. p. 103-269.

15. Demeter Z, Palade EA, Bologh E, Jakab C, Farkas R, Tanczos B, et al. Postmortal small Babesia-like morphology of Babesia canis - short communication. Acta Vet Hung. 2011;59:427-31.

16. Vial HJ, Gorenflot A. Chemotherapy against babesiosis. Vet Parasitol. 2006;138:147-60.

17. Amar CFL, Chalmers RM, Elwin K, Tynan P, McLauchlin J. Blinded evaluation of DNA extraction and genotyping of stained Cryptosporidium on glass slides. Lett Appl Microbiol. 2002;35:486-8.

18. Motazedian H, Karamian M, Noyes HA, Ardehali SDNA. extraction and amplification of Leishmania from archived, Giemsa-stained slides, for the diagnosis of cutaneous leishmaniasis by PCR. Ann Trop Med Parasitol. 2002;96:31-4.

19. Pandey K, Pandey BD, Mallik AK, Kaneko O, Uemura $H$, Kanbara $H$, et al. Diagnosis of visceral leishmaniasis by polymerase chain reaction of DNA extracted from Giemsa's solution-stained slides. Parasitol Res. 2010;107:727-30.

20. Volpini AC, Marques MJ, Lopes dos Santos S, Machado-Coelho GL, Mayrink W, Romanha AJ. Leishmania identification by PCR of Giemsa-stained lesion imprint slides stored for up to 36 years. Clin Microbiol Infect. 2006;12:815-8.

21. Meyer $\mathrm{R}$, Hoffelein C, Candrian U. Polymerase chain reaction restriction fragment length polymorphism analysis: A simple method for species identification in food. J AOAC Int. 1995:78(6):1542-51.

22. Cacciò SM, Antunović B, Moretti A, Mangili V, Marinculić A, Rafaj Barić R, et al. Molecular characterization of Babesia canis canis and Babesia canis vogeli from naturally infected European dogs. Vet Parasitol. 2002;106:285-92.

23. Selanec J, Torti M, Šmit I, Mayer I, Kuleš J, Jović I, Mrljak V. Novije spoznaje o babeziozi pasa. Vet stanica. 2012;43:497-505

24. Li J, Wirtz RA, McCutchan TF. Analysis of malaria parasite RNA from decade-old Giemsa-stained blood smears and dried mosquitoes. Am J Trop Med Hyg. 1997:57:727-31.

\section{Submit your next manuscript to BioMed Central and we will help you at every step:}

- We accept pre-submission inquiries

- Our selector tool helps you to find the most relevant journal

- We provide round the clock customer support

- Convenient online submission

- Thorough peer review

- Inclusion in PubMed and all major indexing services

- Maximum visibility for your research

Submit your manuscript at www.biomedcentral.com/submit
Biomed Central 